\title{
Mathematical modeling of state support of investment process
}

\author{
Chernyatieva R.R. \\ Ufa State Petroleum Technological University \\ Ufa, Russia \\ chernyatievarr@yandex.ru
}

\begin{abstract}
In this article, the mathematical model of the state support of investments is analyzed. The target function represents the maximal tax budgetary payments; the system of restrictions consists of linear and nonlinear functions, which corresponds to normative data. The maximal tax efficiency portfolio is generated by the principle of Pareto. The relevance of the proposed model follows from the current development of Russia and the situation on the international financial markets. In this regard, mechanisms and models are needed to assess the effectiveness of the funds invested by the state. The author proposes and analyzes a mathematical model of state support for investments. The target functional is the maximum tax budget allocations, the system of restrictions - linear and nonlinear functions, corresponding to regulatory data. It is proved that the formulated problem is a convex programming problem. According to the Pareto principle, an optimal set of basic criteria characterizing the financial stability of the investment project is determined. The portfolio is formed by the criterion of maximum tax efficiency. To solve the problems of assessing the effectiveness of investment projects today, there is a wide range of instrumental methods. Thus, using the mathematical model of state support for investments, the state obtains a mechanism to increase the efficiency of its activities, to support the modernization and technical re-equipment of enterprises in the most painless ways without losing its independence, and also to predict the consequences of its actions on the monetary policy being implemented.
\end{abstract}

Keywords - investments; the investment project; mathematical model; principle of Pareto; an investment portfolio; state financing;

\section{INTRODUCTION}

The relevance of the proposed model follows from the current development of Russia and the situation on the international financial markets $[1,2]$.

1. Favorable conjuncture in the world oil markets allowed the Government of Russia to take one of the priority directions of the state policy for the development of nanotechnologies and technology parks, as well as support for investments [3, 4].

2. Until recently, the management of most enterprises in financing their investment policy benefited from the use of cheap loans from foreign banks, but the mortgage crisis in the US this summer led to the fact that most banks became more conservative towards borrowers and tightened the requirements for them. Not to mention that most of the planned IPOs in 2007 are also postponed [5, 6].
3. The forthcoming Russia's accession to the WTO in the near future requires the state and the majority of branchforming enterprises to start thinking about competition on the part of Western companies and the need for investment $[7,8]$.

In this regard, mechanisms and models are needed to assess the effectiveness of the funds invested by the state [9].

\section{THEORETICAL ANALYSIS}

The author proposes and analyzes a mathematical model of state support for investments. The target functional is the maximum tax budget allocations, the system of restrictions linear and nonlinear functions, corresponding to regulatory data [10]. It is proved that the formulated problem is a convex programming problem [11]. According to the Pareto principle, an optimal set of basic criteria characterizing the financial stability of the investment project is determined [12]. The portfolio is formed by the criterion of maximum tax efficiency $[13,14]$.

To solve the problems of assessing the effectiveness of investment projects today there is a wide range of instrumental methods [15]. Each of them allows one to make a comprehensive analysis of alternative options and to select the best one for any criteria.

The main part of the existing models in use has essentially the same methodological basis: the calculation of the internal rate of effectiveness, the accounting of risk, as well as individual elements of the financial mechanism. The ability to implement investment projects, as well as the results achieved, depends to a large extent on state support, with certain guarantees and benefits. Thus, the task of state support of investments arises. As a normative document, the main law of the Republic of Bashkortostan "On the Republican Budget of the Republic of Bashkortostan" is used:

Provision of state guarantees to investors at the expense of the Development Budget funds and allocation of funds for financing of the main projects at the expense of the Development Budget funds are implemented at a higher level of return to the national budget for each ruble of state guarantees, provided by the Development Budget funds or allocated cash Funds, financing the investment project at the expense of the Development Budget funds.

The task of this work is to create a mathematical model of state support for investments in the competitive selection of investment projects that are applied for state funding, the 
development of a computational algorithm and computer implementation, and the computation of experiments for real systems.

Let $n$ be investment projects that claim to provide government support. It is necessary to find the amount of public investment that will ensure the greatest budgetary efficiency. The purpose of this model is to determine the optimal share of state participation in the use of various forms of financing (tax credit, budget loans, budget loans, etc.) and, at the same time, obtaining the maximum relative to state guarantees of tax return.

\section{MethodOLOGY}

Let us describe a mathematical model.

Let us introduce the criterion for assessing state support, which follows from this law. For the state, the most important criterion is tax deductions to the budget.

The criterion for assessing the effectiveness of investment - the deduction of tax revenues from the implementation of an investment project - will be called the coefficient of tax efficiency of state guarantees (COTE) denoted by $\mathrm{K}_{\mathrm{G}}$.

A separate element of the payment flow in year $t$ is:

$$
R_{t}=(G-C)-(G-C-D) * T .
$$

Here $\mathrm{G}$ - gross (income from the project);

C - recurrent costs;

D - income to which benefits apply;

$\mathrm{T}$ - the tax rate.

Investment costs and revenues are reduced to one point in time t. Let us introduce the coefficient of state guarantees (CSG) $\alpha_{\mathrm{G}}$ :

$$
0<\alpha_{\mathrm{G}} \leq 1 \text {. }
$$

$\alpha_{\mathrm{G}}=1-$ the investment project is entirely financed by the state;

$\alpha_{\mathrm{G}} \neq 0$ - by definition, lack of public funding;

$P$ - the size of investment capital;

$\mathrm{P}^{*} \alpha_{\mathrm{G}}-$ part of the investment capital due to state support, ie, $\alpha_{G}$ - weight for the corresponding argument. Then the optimizing functional can be written in the form:

$$
K_{G}^{i}=\frac{\left(G_{i}-C_{i}-P_{i}\left(1-\alpha_{G}^{i}\right)+A P_{i} \alpha_{G}^{i}+\Delta D\right) * T}{P_{i} \alpha_{G}^{i}} \rightarrow \max ,
$$

A $-1.5 \%$ of the amount of issued guarantees, if the entity is not a recipient of the funds of the republican budget;

$\mathrm{T}$ - tax rate of $19 \%$ for enterprises and $27 \%$ for intermediaries;

\section{$\Delta \mathrm{D}$ - other preferential taxes;}

$i$ - number of the investment project participating in the tender for obtaining state guarantees.

Formula (1) is the ratio of the amount of tax deductions to the amount of state guarantees, i.e., the return of tax revenues to the ruble provided by state guarantees (in accordance with the law of the Republic of Belarus "On the Republican Budget of the Republic of Belarus").

For investigating the behavior of objective function (1), let us represent it in the form of a fractional-rational, depending on $P_{i}$ and $\alpha_{G}^{i}$ :

$$
K_{G}^{i}=\frac{B_{1}^{i}-P_{i}\left(1-\alpha_{G}^{i}\right)+B_{2}^{i} \alpha_{G}^{i}}{P_{i} \alpha_{G}^{i}}=\frac{B_{1}^{i}}{P_{i} \alpha_{G}^{i}}-\frac{P_{i}\left(1-\alpha_{G}^{i}\right)}{P_{i} \alpha_{G}^{i}}+\frac{A B_{2}^{i} \alpha_{G}^{i}}{P_{i} \alpha_{G}^{i}},
$$

where $B_{1}^{i}=G_{i}-C_{i}+\Delta D$ - profit;

$P_{i}\left(1-\alpha_{G}^{i}\right)$ - the amount of investment paid by the borrower;

$B_{2}^{i}$ - tax deduction of the subject who is not the recipient of the republican budget. Then the coefficient of tax efficiency (COTE) for the i-th investment project will look like:

$$
K_{G}^{i}=\frac{B_{1}^{i}}{P_{i} \alpha_{G}^{i}}-\frac{1}{\alpha_{G}^{i}}+1+\frac{B_{2}^{i}}{P_{i}} \rightarrow \max .
$$

Let us introduce a system of restrictions describing the limit of state financing, as well as the conditions for granting state guarantees depending on the borrower's own funds:

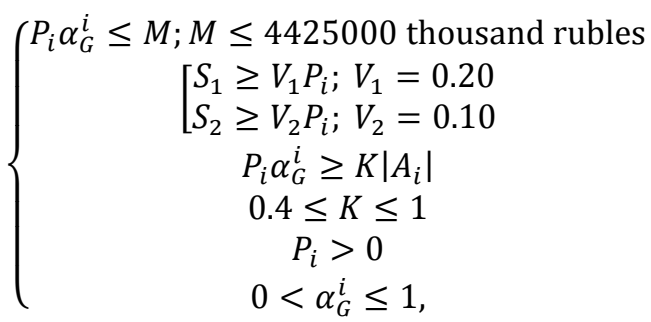

where $M-$ the financing limit;

$S$ - the borrower's own funds;

$V$ - tax rate;

$A$ - risk capital, the absolute value of the maximum negative balance.

Let us study this optimization problem. Obviously, this is a nonlinear programming problem.

1. If $B_{1}^{i}>P_{i}$, that is, the size of the investment is less than the profit without deductions, then the coefficient of tax efficiency of state guarantees - objective function (2) increases if $\alpha_{G}^{i}$ decreases; i.e. the larger the COTE is, the smaller the share of CSG is.

2. If $B_{1}^{i}<P_{i}$, that is, the amount of investment is greater than the profit without deductions, then the coefficient of tax efficiency of state guarantees decreases, if $\alpha_{G}^{i}$ decreases; i.e. the smaller the COTE is, the larger the share of CSG is.

The proposed model is easy to formalize for various forms of public financing: tax credit, budgetary credit, etc., their combinations, taking into account the limitations of funding. In these cases, the numerator and the denominator of the objective function will change to the corresponding indicators, and inequalities of the corresponding funding limits will appear in the system of restrictions. 
The formulation and analysis of the given mathematical model with a certain system of initial assumptions allow evaluating, substantiating and implementing optimal investment projects in specific conditions.

Let us transform objective function (1) as follows:

$$
A_{i}=G_{i}-C_{i}+\Delta D .
$$

Then there is a convex function:

$$
K_{G}^{i}=\left(\frac{A_{i}}{P_{i} \alpha_{G}^{i}}-\frac{1}{\alpha_{G}^{i}}+C_{i}\right) \rightarrow \max .
$$

Studying the Hessian of the objective function, one has:

$$
H(P, \alpha)=\left\|\frac{\partial^{2} K_{G}^{i}(P, \alpha)}{\partial P_{i^{*}}^{*} \alpha_{G}^{i}}\right\|_{m * m}=\frac{A_{i}}{P_{i}^{3} * \alpha_{G}^{i}}\left(\frac{3 A_{i}}{P_{i}}-4\right) .
$$

From expression (4) for the Hessian of the objective function, it follows that for $A_{i}>\frac{4}{3}$ on the investment size for the period under consideration, the Hesse matrix has positive definiteness at all points of admissible solutions. This means that this problem belongs to the class of convex programming problems. Hence, objective function (3) is strictly convex and has no more than one stationary point, which is a point of local and global extremum. From an economic point of view, this means that if this condition is fulfilled, the return on the invested capital is greater than the investment amount - this means that the project is profitable and its investments are profitable. Let us analyze possible situations.

1. If $\mathrm{A}>0$, then the profit is positive, and the investment project is cost-effective, then if condition $A_{i} \geq \frac{4}{3} P_{i} H(P, \alpha) \geq 0$ is satisfied, then the objective function is convex and has an extremum in the range of constraints of variables.

2. If $\mathrm{A}>0$ and $A_{i}<\frac{4}{3} P_{i}$, then $H(P, \alpha)<0$, therefore, there is no objective function of extrema.

3. If $\mathrm{A}<0$, that is, the project is unprofitable, then $\left|A_{i}\right| \geq$ $\frac{4}{3} P_{i}$, therefore, the objective function has an extremum in the range of constraints of variables.

The author chose the algorithm of the steepest descent method. According to this algorithm, the program complex is written in Delhi language, which satisfies a high level of service and allows solving various tasks of this type.

\section{EXPERIMENTAL PART}

The model was tested for adequacy by the example of real investment projects, given in Table 1.

There are results of the solution of the optimization task for maximizing the coefficient of tax efficiency (COTE) and the coefficient of state guarantees (CSG) on real investment projects.
TABLE I. CRITERIA FOR THE EFFECTIVENESS OF INVESTMENT PROJECTS

\begin{tabular}{|l|l|l|l|l|}
\hline$№$ & $\begin{array}{l}\text { Name of the investment } \\
\text { project }\end{array}$ & $\begin{array}{l}\text { Real } \\
\text { COTE }\end{array}$ & $\begin{array}{l}\text { Calculated } \\
\text { CSG }\end{array}$ & $\begin{array}{l}\text { Estimate } \\
\text { COTE }\end{array}$ \\
\hline 1 & $\begin{array}{l}\text { Construction of the } \\
\text { production of } \\
\text { "Italbashkiremika", } \\
\text { Oktyabrskiy }\end{array}$ & 0.23 & 0.2 & 1.2 \\
\hline 2 & $\begin{array}{l}\text { Completion of construction } \\
\text { of the Kumertau woolen } \\
\text { spinning mill of the Republic } \\
\text { of Bashkortostan }\end{array}$ & 0.26 & 0.7 & 0.5 \\
\hline 3 & $\begin{array}{l}\text { JSC "Caustic" (shop for the } \\
\text { production of ethylene) }\end{array}$ & 0.004 & 0.4 & $\begin{array}{l}\text { Close to } \\
\text { zero }\end{array}$ \\
\hline
\end{tabular}

Table 2 analyses the specific data of JSC Caustic.

TABLE II. INDICATORS OF JSC "CAUSTIC"

\begin{tabular}{|l|l|l|l|}
\hline № & K1 - profit & $\begin{array}{l}\text { K2 - investment } \\
\text { capital }\end{array}$ & $\begin{array}{l}\text { K3 - tax } \\
\text { investment } \\
\text { deductions }\end{array}$ \\
\hline 1 & -10479.47 & 501.50 & 15383.42 \\
\hline 2 & 2924.10 & 438.81 & 16897.67 \\
\hline
\end{tabular}

In Fig. 1, members of the cash flow stream are viewed as stand-alone investment projects in the period of time-a quarter.

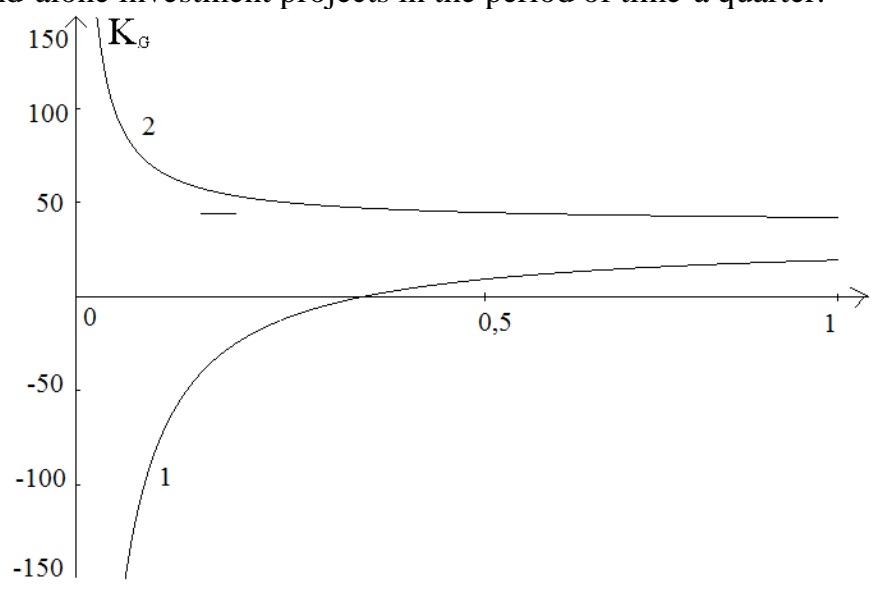

Fig. 1. Dependence of the coefficient of tax efficiency (COTE) KG on the coefficients of state guarantees (CSG) $\alpha_{\mathrm{G}} .1$ - dependence curve for quarter 1 ; 2 - dependence curve for quarter 2

Comparison of the curves of the tax efficiency of state financing, depending on the share of its participation and the comparison of the indicators $K_{G}$ and $\alpha_{G}$, determines the preference of investment project 2 , since state participation share $\alpha_{G}=0.04$, or $4 \%$ and the coefficient of tax efficiency will be maximum in comparison with another curve. From the point of view of the tax efficiency of state guarantees, Project 1 is unsatisfactory. In it, investment capital exceeds profit, and investment in such project of cash is unprofitable.

The developed model is tested based on two investment projects:

- production of vinyl chloride at JSC "Caustik", Sterlitamak;

- reconstruction and restoration of the Trade Series in Ufa. 
If one considers the average estimates of the two proposed investment projects, then with own funds of $\$ 313.44$ and $\$$ 1003.00 , the profit was $\$ 21.559 .09$ and $\$ 62.386 .24 ; \alpha_{1}=0.19$ and $\alpha_{2}=0.26 ; P_{1}=1819 \$$ and $P_{2}=1894 \$$; COTE $=66.84$ and $\mathrm{COTE}=169.38$. The project that has the greatest tax efficiency is the best. The importance of the selection criteria depends on the person who made the decision (PMD), analyzing the payback period, the size of the requested investment, the level of risk, etc.

There are other criteria for assessing the effectiveness of investments, they are all contradictory; hence, let us use the Pareto method. The authors' task is to define the Pareto set for the main economic indicators that characterize the financial sustainability of the project, which claims to be supported by the state.

Let $N$ be investment projects. Each of them is associated with $K$ numerical characteristics, i.e. $K$ indicators that map each investment project. Let $x^{*}$ be some choice and there is a choice of $x$, such that for all criteria there are inequalities:

$$
f_{i}(x) \geq f_{i}\left(x^{*}\right), i=1, \ldots, N,
$$

And at least one of the inequalities is strict.

Among the set of all admissible alternatives, it is necessary to find those, in the implementation of which it is possible to improve the quantitative characteristics of the indicators in comparison with the existing ones. The number of contestants is unlimited.

Let us consider the set optimization problem. The desired values of the criteria must be fixed. The author will rank the projects according to the values of the main indicators and record them in the table in the order of their decrease. According to the Pareto principle, the best investment project is that for which there is no project for the criteria indicators worse than this, and at least one indicator is better.

The proposed initial matrix is formed according to the existing international methodology for assessing UNIDO investments and the Basic Law on the Development Budget. All quantitative indicators are ranked by the decision maker.

Thus, there is a multi-criteria of the decision-making task.

This task is multicriteria - in terms of certainty for 8 indicators, and the goal consists in optimizing (maximizing or minimizing) all these indicators. Pareto as the optimal investment project is the most beneficial for the DM in accordance with the orderly importance of the financial evaluation of the competitive investment project, which claims to be supported by the state.

For the Pareto relation, all criteria are equal and permutations of estimates do not change the basic inequalities of binary relations, which makes the application of this method more preferable and universal in comparison with others.

\section{NUMERICAL RESULTS AND DISCUSSION}

The author has written a program for the selection of the optimal solution based on the Pareto principle in the competitive selection of investment projects, claiming state support. The program has been tested for adequacy in several real investment projects: Kaustik JSC, Sterlitamak, the construction of the shopping complex "Trading Rows" in Ufa, the construction of the production of "Italbashkiremika" in the city of Oktyabrsky. The obtained decisions are formulated in the form of priority in Table 3, where the importance of the criteria determines the positions of competitive projects with the criteria for optimizing alternatives.

TABLE III. RANKED INDICATORS OF A FINANCIAL CONDITION OF THE ENTERPRISE

\begin{tabular}{|l|c|c|c|c|c|c|c|c|}
\hline $\begin{array}{c}\text { Indicators } \\
\text { № of project. }\end{array}$ & COTE & NV & NPV & IRP & PF & PI & Tcp & Xp \\
\hline 1 & 2000 & 920 & 24 & 4000 & 230 & 35000 & 2 & 8 \\
\hline 2 & 10000 & 500 & 12 & 3500 & 200 & 34000 & 3 & 7 \\
\hline 3 & 500 & 300 & 15 & 2800 & 150 & 33000 & 4 & 6 \\
\hline 4 & 100 & 100 & 6 & 2000 & 250 & 32000 & 5 & 4 \\
\hline 5 & 800 & 400 & 8 & 5000 & 300 & 30000 & 4 & 2 \\
\hline 6 & 900 & 500 & 9 & 1500 & 290 & 20000 & 3 & 5 \\
\hline 7 & 1000 & 600 & 10 & 2100 & 180 & 25000 & 1 & 6 \\
\hline
\end{tabular}

Many Pareto solutions include:

1 The contestant is the leader in terms of indicator 1 ; the 1 place is taken by the contestant 5 ;

2 The contestant is the leader in terms of indicator 1 ; the 23 places are taken by the contestants $2 ; 4$

3 The contestant is the leader in terms of indicator 4 place is taken by the contestant 1 ;

4 The contestant is the leader in terms of indicator $3 ; 7 ; 5$ place is taken by the contestant 6 ;

5 The contestant is the leader in terms of indicator $4 ; 5 ; 8 ; 6$ 7 places are taken by the contestants $3 ; 7$;

6 The contestant is the leader in terms of indicator 6 ;

7 The contestant is the leader in terms of indicator:

Analyzing the information received, the LPR sees how much one of the indicators for the others "costs" to increase, the values of which will inevitably worsen.

The proposed methodology for selecting investment projects that claim to support the state allows us to find a solution to a multicriteria task optimizing the investment of public funds based on system analysis in order to obtain maximum tax deductions to the national budget.

A description of the mathematical model with the obtained objective function and the corresponding constraint system was given by the authors in [16] and [17].

To find the portfolio of the highest tax efficiency, it is necessary to obtain a set of effective points, solving the obtained optimization problem.

The proposed method for assessing investment decisions, built on an analysis of the tax efficiency of an investment project based on state guarantees, can be applied not only to determine the appropriateness of using such projects, but also to determine the permissible level of project prices. The main 
difference of the portfolio obtained is that it is formed only from investment projects that have the maximum tax efficiency and the best financial indicators characterizing the financial stability of the investment project. table.

The advantages of the model used are presented in the

TABLE IV. ADVANTAGES AND DISADVANTAGES OF THE MODEL USED

\begin{tabular}{|l|l|}
\hline State & Investor \\
\hline $\begin{array}{l}\text { 1. Using this model allows one: } \\
\text { - "selectively" to invest in some of the most } \\
\text { attractive projects or enterprises; }\end{array}$ & $\begin{array}{l}\text { Using this } \\
\text { model allows: } \\
\text { - to attract cheap } \\
\text { resources fo increase the effectiveness of the state's } \\
\text { projects }\end{array}$ \\
activities in order to spend the funds efficiently \\
and return them, which will lead to an increase in \\
the number of state supported projects; \\
$\begin{array}{l}\text { - to develop a unified system for evaluating } \\
\text { investment projects, which will reduce the } \\
\text { influence of the subjective factor in the allocation } \\
\text { of public funds; } \\
\text { - to use the model for ranking investment projects } \\
\text { of investments. } \\
\text { 2. The proposed mathematical model allows one } \\
\text { to influence the monetary base of the region and is } \\
\text { one of the indirect mechanisms of fiscal policy }\end{array}$ \\
\hline
\end{tabular}

\section{CONCLUSION}

Thus, using the mathematical model of state support for investments, the state obtains a mechanism to increase the efficiency of its activities, to support the modernization and technical re-equipment of enterprises in the most painless ways without losing its independence, and also to predict the consequences of its actions by the monetary policy being implemented.

\section{References}

[1] A.N. Rugina, "An american-british economic, monetary, financial and social stabilization plan. a new vision of how to solve the malaise of the twentieth century in the western world", International Journal of Social Economics, vol. 24, pp. 421-595, 1997.

[2] "Annotated listing of new books", Journal of Economic Literature, vol. 40, pp. 579-720, 2002.

[3] E. Bogdanova, E. Gospodarevskaya, G. Balancev, E. Nikishova, P. Eliseev, A. Maryandyshev, A. Detjen, S.B. Squire, "Cost-effectiveness analysis of lpa-based algorithm for detection of multidrug-resistant tuberculosis (MDR-TB) in Arkhangelsk region (Russian Federation)", International Journal of Tuberculosis and Lung Disease, vol. 18, pp. 492-493, 2014.

[4] T.F. Buss, "The case against targeted industry strategies", Economic Development Quarterly, vol. 13, pp. 339-356, 1999.

[5] R. Santhanam, G.J. Kyparisis, "A decision model for interdependent information system project selection", European Journal of Operational Research, vol. 89, pp. 380-399, 1996.

[6] P. Alfredsson, "Optimization of multi-echelon repairable item inventory systems with simultaneous location of repair facilities", European Journal of Operational Research, vol. 99, pp. 584-595, 1997.

[7] P. Ghandforoush, T.K. Sen, M. Wander, "A decision support system for electric utilities: compliance with clean air act", Decision Support Systems, vol. 26, pp. 261-273, 1999.

[8] G. Hübner-Dick, R. Seidelmann, "Simulating economic sanctions and incentives: hypothetical alternatives of united states policy on south Africa", Journal of Peace Research, vol. 15, pp. 153-174, 1978.

[9] C. Kenny, D. Williams, "What do we know about economic growth? Or, why don't we know very much?", World Development, vol. 29, pp. 122, 2001.

[10] A. Davey, D. Olson, "Multiple criteria decision making models in group decision support", Group Decision and Negotiation, vol. 7, pp. 55-75, 1998.

[11] B. Spotton, "Financial instability reconsidered: orthodox theories versus historical facts", Journal of Economic Issues, vol. 31, pp. 175-195, 1997.

[12] K. Eisenack, J. Kropp, "Assessment of management options in marine fisheries by qualitative modelling techniques", Marine Pollution Bulletin, vol. 43, pp. 215-224, 2001.

[13] J.M. Campa, "Multinational investment under uncertainty in the chemical processing", Journal of International Business Studies, vol. 25, pp. 557-578, 1994.

[14] M. Gorton, F. Guba, "Foreign direct investment (FDI) and the restructuring of the hungarian dairy processing sector", Journal of East West Business, vol. 7, pp. 5, 2001.

[15] Z. Wang, J. Xia, L. Zhang, "Optimal investment for an insurer: the martingale approach", Insurance: Mathematics and Economics, vol. 40, pp. 322-334, 2007.

[16] R.R. Chernyatyeva, "Mathematical modelling of process of the state support of investments. A review of applied and industrial mathematics", vol. 8, p. 722, 2001.

[17] R.R. Chernyatyeva, "Set of Pareto at an estimation of investment projects. A review of applied and industrial mathematics", vol. 10, p. 433, 2003. 